\title{
Use of BIM and Smart Monitoring for buildings' Indoor Comfort Control
}

\author{
Rania Wehbe ${ }^{1, *}$, and Isam Shahrour ${ }^{2}$ \\ ${ }^{1}$ Laboratoire de Génie Civil et géo-Environnement, Université de Lille, 5900 Lille, France
}

\begin{abstract}
Building information modeling (BIM) is the geometric way to present a life cycle construction project including geographic information. Recently, the Internet of Things (IoT) has been progressively used smart buildings in order to enhance living comfort, work productivity and entertainment. However, studies addressing the combination of these two technologies (BIM and IoT) focused on the automatic diffusion of data through sensors to BIM models [1]. Based on American College of Occupational and Environmental Medicine (ACOEM) a great portion of our time is spend inside buildings, in our offices, homes, schools, health care facilities, or in other private or public buildings. Hence the necessity to improve the basic human right to live in a healthy, safe and comfort environment is vital. This paper presents the use of BIM to support complex decisions concerning comfort conditions in buildings. This use is illustrated through a case study concerning a building of the AUST campus in Beirut.
\end{abstract}

\section{Background}

This paper deals monitoring of indoor comfort conditions in buildings. The significance of the subject lies on the impact of indoor conditions on public health and quality of life. Thanks to the development of smart monitoring based on IoT, both occupants and buildings managers could access to real-time data concerning the indoor comfort. Consequently, they have the possibility to take mitigation measurements in the case of deterioration of indoor conditions. Smart monitoring could help also to enhance the indoor security [2].

The real-time survey of indoor comfort conditions faces some difficulties such as realtime management and share of data, 3D visualization of comfort conditions and rapid decision making.

The BIM technology offers large opportunities for the lifecycle management of building [3]. However, it lacks the means to integrate data concerning the immediate environment into the 3D model, that can stock information and improve human comfort. It must be supported by a plug-in to attain the first stage in intelligent building. Kensek confirmed the efficiency of the scripting language Dynamo as a parametric design tool, and successfully used data from Arduino environmental sensors (humidity, $\mathrm{CO} 2$ and sunlight) in the BIM model, while changing 3D model parameters [4].

This paper presents the methodology followed to use of BIM in real-time control of indoor comfort conditions then it provides an illustration of these through an application to a building in the AUST campus in Beirut.

rania.a.wehbe@hotmail.com 


\section{Methodology}

\subsection{Use of BIM for survey comfort conditions}

The methodology followed in this research is illustrated in fig.1. Autodesk Revit Software is used to connect the real time information to the BIM system. Data transfer to the BIM model is conducted through dynamo parametric design script. The key issue to manage and monitor the building is related to linking the Model on Dynamo. The latter is a visual programming tool that works with Revit. Dynamo extends the power of Revit by providing access to the Revit API (Application Programming Interface) in a more accessible manner. Rather than typing code, Dynamo generates a script by manipulating graphical elements called nodes.

BIM model will manage and control the indoor comfort parameters of the building. First of all, all existing sensors are linked to Arduino software that generate the data periodically in a CSV form. Using Dynamo Revit the software will be able to interact in real-time with the CSV file. This database will help the Revit by mean of Dynamo to locate the coordinates of the sensors, their readings and display colors depending on the comfort conditions.

Dynamo is capable of detecting the comfort parameters (temperature, humidity, brightness, noise) of each room in the model and compare the values with the standards. If the comfort parameters do not satisfy standards values, dynamo will send a message visualizing the $3 \mathrm{D}$ model containing the rooms affected by abnormal values. In addition, the user can to follow the sensors data.

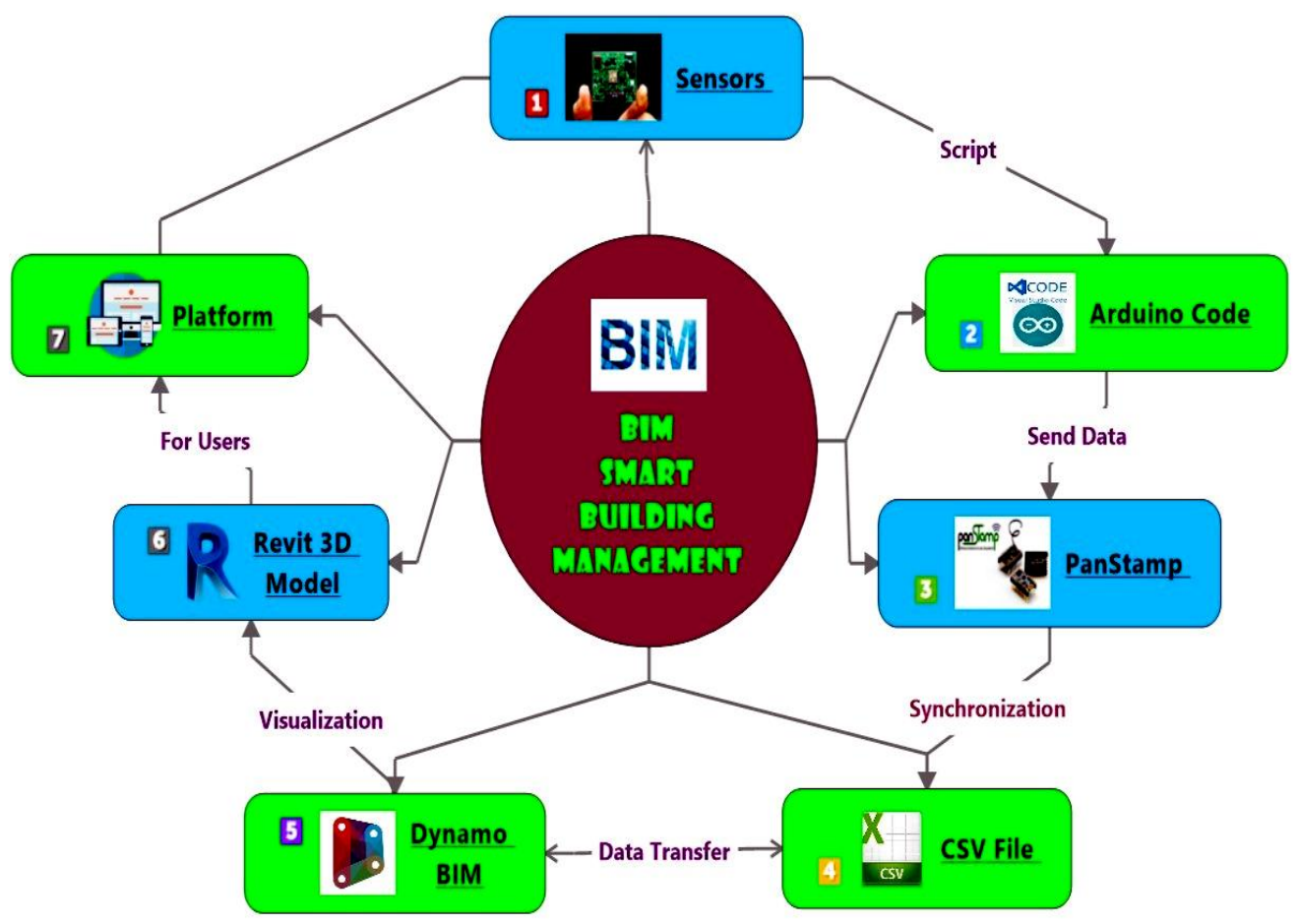

Fig. 1. BIM Smart Building Management Prototype. 


\subsection{Comfort parameters}

The comfort parameters taken into consideration in this research concern the temperature, humidity, noise and brightness. The comfort indoor temperature for human beings is between 19 and 26 degrees Celsius.

On the other hand, even if the temperature is maintained and controlled between the ideal ranges, humidity in the air can affect the comfort in the buildings no matter what type of existing climate. Having the right level of moisture in the air ensure that the HVAC system in the building are working efficiently. The average humidity in summer should range between $30 \%$ to $45 \%$ while in winter, humidity should be below $40 \%$ [5]. Controlling humidity in buildings is very important, because the right humidity makes the air feel cooler in summer and warmer in winter, therefore it will increase the efficiency of heating and cooling system and reduce energy consumption.

Decisions concerning the indoor comfort are based on Predicted Mean Vote (PMV), knowing that the PMV is a common metric for measuring the comfort level of an indoor environment according to ISO 7730 [6]. PMV can be calculated based on factors including the clothing insulation and body's metabolic rate, besides environmental parameters (air temperature, humidity, average radiant temperature, and relative air velocity). PMV formula is written through Python in Dynamo to analyze PMV values on BIM Model. When PMV $=0$, the indoor environment is in the best thermal comfort state, moreover the PMV should be between -0.5 and 0.5 based on code.

According to WHO large noises can affect largely human being comfort and productivity, because human beings to be prolific in calm environment. Based on Tocci Room Noise Criteria, indoor noises should not exceed $55 \mathrm{db}$ [7].

The indoor light is essential and vary depending on the indoor human activity. However, the light level should be in the range of 500 to 1000 lux.

\section{Application to building A of the AUST}

The prototype was at first tested in building A in AUST university, faculty of engineering, for the temperature, humidity and brightness. Sensors record and transmit data at 5 minutes time-interval. According to standards, the temperature is acceptable, the room is slightly humide.

Table 1: Data collected from the sensors

\begin{tabular}{|c|c|c|c|c|}
\hline $\begin{array}{c}\text { Sensor } \\
\text { Name }\end{array}$ & Time & $\begin{array}{c}\text { Temperature } \\
\text { (Celsius) }\end{array}$ & Humidity \% & Brightness (Lux) \\
\hline $0 \mathrm{~A}$ & $14 / 06 / 201919: 04: 21$ & 24.9 & 50.3 & 355 \\
\hline 25 & $14 / 06 / 201919: 04: 25$ & 24.5 & 53.3 & 266 \\
\hline $0 \mathrm{~A}$ & $14 / 06 / 201919: 09: 22$ & 24.8 & 49.9 & 290 \\
\hline 25 & $14 / 06 / 201919: 09: 26$ & 24.5 & 52.7 & 232 \\
\hline $0 \mathrm{~A}$ & $14 / 06 / 201919: 14: 23$ & 24.8 & 50.6 & 350 \\
\hline 25 & $14 / 06 / 201919: 14: 26$ & 24.4 & 53.5 & 252 \\
\hline $0 \mathrm{~A}$ & $14 / 06 / 201919: 19: 24$ & 24.7 & 51.1 & 267 \\
\hline 25 & $14 / 06 / 201919: 19: 27$ & 24.4 & 53.7 & 256 \\
\hline
\end{tabular}


Table 1 shows an example of recorded data. The temperature is around $24^{\circ}$, while the humidity varies between 49.9 and $53.7 \%$. The brightness varies between 252 and 355 LUX.

Fig. 2 shows the 3D BIM with several dynamo script based on different functions, sensor information, colors based on the PMV values, alert notification, charts representing recorded values.

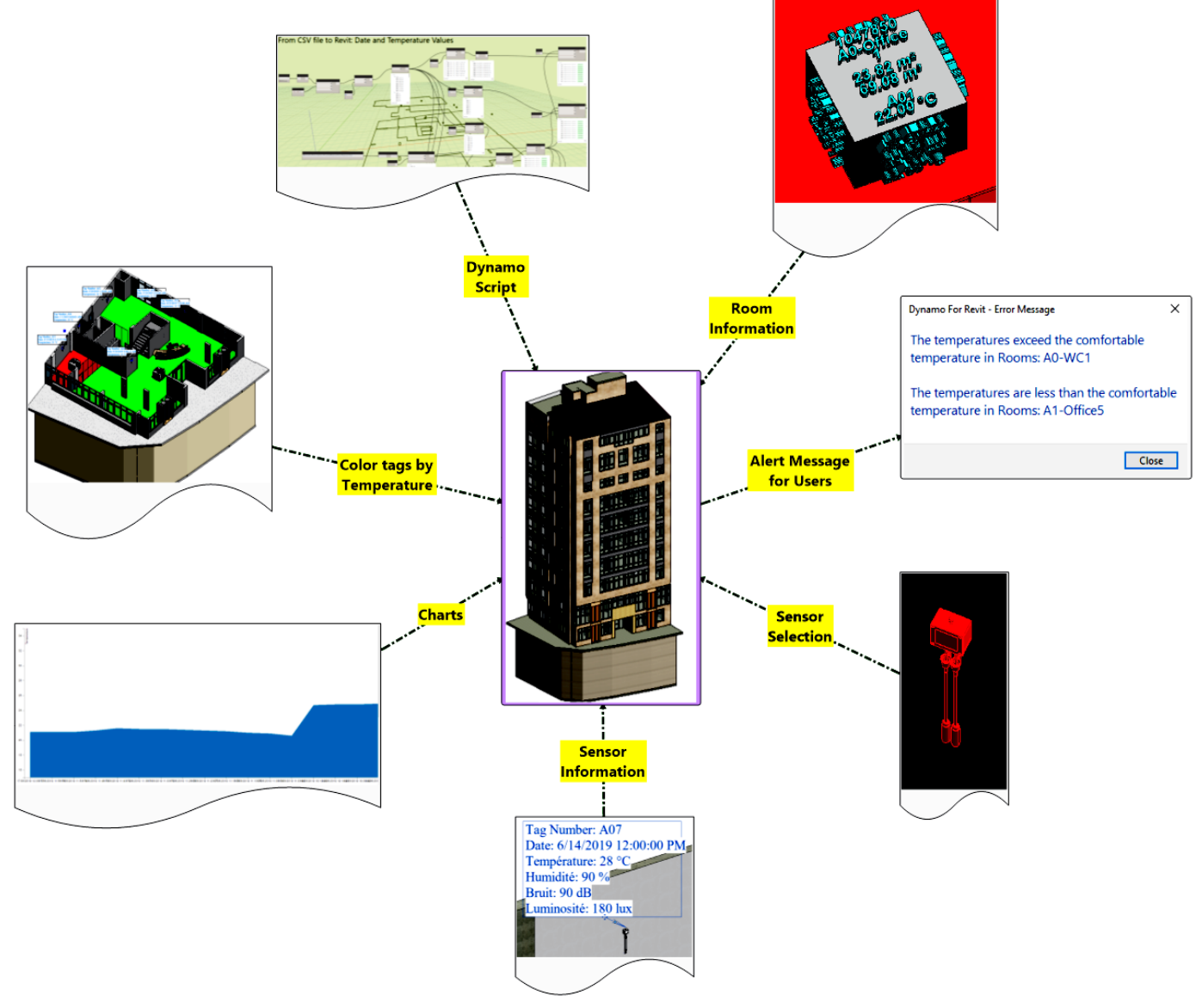

Fig. 2. Summary prototype function

\section{Conclusion}

This paper presented a system that combines BIM and smart sensors to control indoor comfort in buildings. This system allows a real-time survey of indoor comfort parameters as well as the $3 \mathrm{D}$ visualization of comfort parameters and the quality of these conditions with respect to buildings standards. The system was tested in Building A of the AUST campus in Beirut. The test showed good performances of this system in controlling the comfort conditions with respect to the quality of life and energy consumption.

Work is under progress to extend the capacity of this system to safety through monitoring of indoor hazards sources such as indoor air quality, electrical faults, fire, gas and water leak and space access. 


\section{References}

1. K.-M. Chang, R.-J. Dzeng et Y.-J. Wu, Preprints 8, 1086-1101 (2018)

2. R. Wehbe et I. Sahrour, MATEC Web Conf. 281, 01013 (2019)

3. S. Azhar, M. Khalfan, T. Maqsood, AJCEB 12, 15-28 (2012)

4. K. Kensek, Inf Constr, 66 (2014)

5. S. Unsdorfer, (2018). Available: https://www.centralhtg.com/blog/managing-homehumidity-for-maximum-comfort

6. ISO, Management 3, 605-615 (2005)

7. C. Hansen, (2019). Available: https://www.archtoolbox.com/representation/architectural-concepts/architecturalacoustics-acceptable-room-levels.html 